\title{
Numerical Study on the Effects of Contraction Ratio in a Two-Phase Flow Injection Nozzle
}

\author{
Haider Ali' ${ }^{1}$, Kyung Won Kim ${ }^{1}$, Jae Sik Kim² ${ }^{2}$ Jong Yun Choi ${ }^{3}$, Cheol Woo Park ${ }^{1^{*}}$ \\ ${ }^{1}$ School of Mechanical Engineering, Kyungpook National University, Daegu, Korea \\ ${ }^{2}$ Podomaul Co., Ltd., 1190 Kumchang-Ro, Daechang-Myon, Yeongcheon-Si, Korea \\ ${ }^{3}$ B.C.M. Co., Ltd., 81 Yeomsaekgongdancheon-Ro, Seo-Gu, Daegu, Korea \\ Email: ${ }^{*}$ chwoopark@knu.ac.kr
}

Received 24 November 2015; accepted 5 March 2016; published 8 March 2016

Copyright (C) 2016 by authors and Scientific Research Publishing Inc.

This work is licensed under the Creative Commons Attribution International License (CC BY). http://creativecommons.org/licenses/by/4.0/

(c) (i) Open Access

\section{Abstract}

The Euler-Euler numerical method was used to investigate the effects of contraction ratio on twophase flow mixing with mass transfer in the flow injection nozzle. The geometric shape of the nozzle was modified to improve carbonation efficiency. A gas inlet hole was created to increase the flow mixing of $\mathrm{CO}_{2}$ with water. A nozzle throat was also introduced to increase the gas dissolution by increasing flow rates. Various contraction ratios of nozzle throat, inlet gas and liquid velocities, and gas bubble sizes were employed to determine their effects on gas hold-up, gas concentration, and mass transfer coefficient. Results revealed that the flow injection nozzle with high contraction ratios improved carbonation because of high gas hold-up. Gas concentration was directly related to contraction ratio and gas flow velocities. Carbonation reduced when high liquid velocities and large gas bubbles were employed because of inefficient flow mixing. This study indicated that flow injection nozzle with large contraction ratios were suitable for carbonation because of their ability to increase gas hold-up, gas concentration, and mass transfer coefficient.

\section{Keywords}

Flow Injection Nozzle, Nozzle Throat, Contraction Ratio, Gas-Liquid Flow, Mass Transfer

\section{Introduction}

Carbonated beverages are prepared by dissolving $\mathrm{CO}_{2}$ in water with minimum amount of gas bubbles produced.

"Corresponding author.

How to cite this paper: Ali, H., Kim, K.W., Kim, J.S., Choi, J.Y. and Park, C.W. (2016) Numerical Study on the Effects of Contraction Ratio in a Two-Phase Flow Injection Nozzle. Open Journal of Fluid Dynamics, 6, 1-10. 
Carbonating machines generally employ a flow injection nozzle to supply water during continuous carbonation. Carbonation efficiency can be increased by improving the dissolution of $\mathrm{CO}_{2}$ in water. However, $\mathrm{CO}_{2}$ is not completely dissolved in the carbonating tank because of high gas and water flow rates. Therefore, a small opening is created in the flow injection nozzle to allow $\mathrm{CO}_{2}$ to enter into the nozzle and mix effectively with water. The aforementioned geometrical modification helps to increase gas dissolution by increasing the interaction time of gas with water. The gas bubbles tend to rise vertically and gather in the center of the nozzle at high gas flow rates, thereby leading to liquid circulation. Radial gas accumulation causes flow recirculation in the nozzle. Flow recirculation is essential for carbonation because it facilitates gas dissolution [1] [2].

Carbonation significantly depends on the solubility of $\mathrm{CO}_{2}$ in water. As such, mass transfer in these systems must be assessed for design optimization. The mass transfer coefficient of $\mathrm{CO}_{2}$ must be estimated in the flow injection nozzle to quantify mass transfer rate between the gas and liquid interface boundary [3]. Deckwer et al. [4] reported that mass transfer coefficient depends on the geometric shape of the sparger or nozzle used for flow injection. The mass transfer coefficient increases with increasing gas flow rates but decreases when gas and liquid are mixed together with a mechanical agitation device [5]. Several numerical studies were conducted on various industrial applications of two-phase flow by using the famous Euler-Euler two-fluid model because of the complexity and immense cost involved in the experimental work. Chakraborty et al. [6] used the Euler-Euler model to examine the influence of gas flow velocity, reactor geometry, and sparger arrangement on the hydrodynamic properties of the reactor. The results suggested the use of low gas flow rates and uniformly distributed gas spargers to improve the performance of the two-phase reactor [6]. Therefore, the design of the gas sparger or injecting nozzle is of considerable importance for increasing mass transfer coefficient and gas hold-up to enhance carbonation. Moreover, the throat of the flow injection nozzle is considerably important, and the throat area (contraction ratio) can be varied to enhance carbonation by increasing gas dissolution in water. Alves et al. [7] investigated the effect of contraction ratio on the overall features of different flow types; they reported that liquid recirculation strongly depended on contraction ratio and increased with decreasing contraction ratio [7]. Evan and Walters [8] studied the effect of three different contraction ratios. Liquid recirculation is formed and dominated in the case of high contraction ratios [8]. Therefore, contraction ratio is an important parameter in the design of flow injection nozzles and can be used to enhance carbonation. We previously investigated flow mixing in the carbonating tank to improve carbonation with the use of the same Euler-Euler methodology [9]. However, flow mixing in the injecting nozzle and the effect of contraction ratio on hydrodynamic properties were not considered in our previous work.

The study investigates the effect of contraction ratio on gas-liquid turbulent flow with mass transfer in the flow injection nozzle. An inlet hole for $\mathrm{CO}_{2}$ gas was constructed in the nozzle to increase the interaction time of gas with water. The shape of the water nozzle was further modified by introducing a nozzle throat to enhance gas dissolution. The throat area of the nozzle was varied to examine the effect of contraction ratio on the flow mixing phenomenon. Various contraction ratios of nozzle throat, inlet gas and liquid velocities, and gas bubble sizes were employed to determine their effects on gas hold-up, liquid velocity, gas concentration, and mass transfer coefficient.

\section{Mathematical Modeling}

A 2D model of the flow injection nozzle with a length $(L)$ of $0.055 \mathrm{~m}$ and a diameter $(D)$ of $0.006 \mathrm{~m}$ is presented in Figure 1. The inlet for $\mathrm{CO}_{2}$ gas possesses a length of $0.003 \mathrm{~m}$. A nozzle throat with a length $(l)$ of $0.009 \mathrm{~m}$ and a diameter $(d)$ of $0.0023 \mathrm{~m}$ was introduced to enhance gas dissolution. Figure 1 demonstrates the nozzle bend with the inner $(r)$ and outer $(R)$ radii of curvatures of 0.0078 and $0.0015 \mathrm{~m}$, respectively. The geometrical effects of nozzle were studied using a dimensionless number, namely, contraction ratio (CR), which is given below:

$$
\text { Contraction ratio }(\mathrm{CR})=\frac{\text { Nozzle inlet diameter }(\mathrm{m})}{\text { Nozzle throat diameter }(\mathrm{m})}=\frac{D}{d} .
$$

The study considered three CRs (i.e., 2, 3, and 4) with different gas and water flow rates and gas bubble sizes to examine the effect of CRs on the flow mixing process of $\mathrm{CO}_{2}$ gas with water in the flow injection nozzle.

\subsection{Gas-Liquid Flow Modeling}

The study used the Euler-Euler methodology to model two-phase flow in the flow injection nozzle because of 


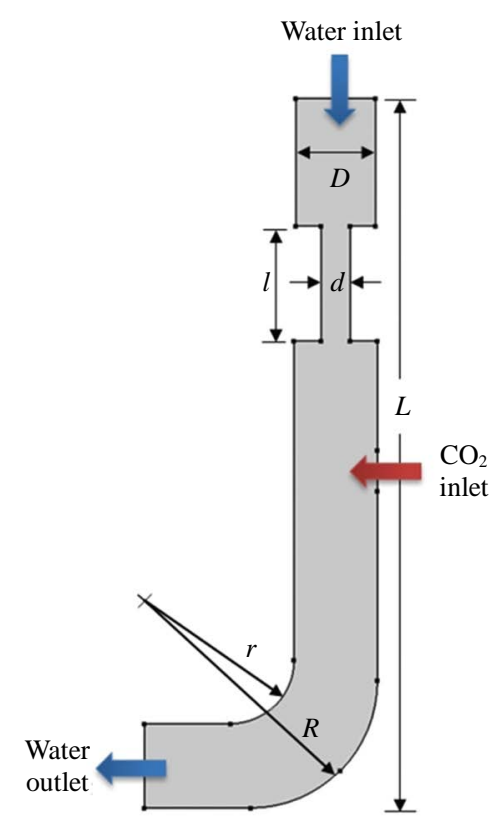

Figure 1. Computational models of the flow injection nozzle.

the ability to track average phase concentration [10] [11]. The governing equations of continuity and momentum transport are as follows:

$$
\begin{aligned}
& \rho_{l}\left(\nabla \cdot u_{l}\right)=0 \\
& \varphi_{l} \rho_{l} \frac{\partial u_{l}}{\partial t}+\varphi_{l} \rho_{l} u_{l} \cdot \nabla u_{l}=-\nabla p+\nabla \cdot\left[\varphi_{l} \mu_{l}\left(\nabla u_{l}+\left(\nabla u_{l}\right)^{\mathrm{T}}\right)\right]+\varphi_{l} \rho_{l} g \\
& \frac{\partial \rho_{g} \varphi_{g}}{\partial t}+\nabla \cdot\left(\rho_{g} \varphi_{g} u_{g}\right)=-m_{g l}
\end{aligned}
$$

where $\varphi$ represents the hold-up $\left(\mathrm{m}^{3} / \mathrm{m}^{3}\right), \rho$ is the density $\left(\mathrm{kg} / \mathrm{m}^{3}\right), u$ is the velocity $(\mathrm{m} / \mathrm{s}), \quad p$ is the pressure (Pa), $\mu$ is the dynamic viscosity (Pa-s), $g$ is the gravity vector $\left(9.81 \mathrm{~m} / \mathrm{s}^{2}\right)$, subscripts $l$ and $g$ are the liquid and gas phases, respectively, and $m_{g l}$ is the mass transfer rate from gas to liquid $\left(\mathrm{kg} / \mathrm{m}^{3} \cdot \mathrm{s}\right)$.

Ideal gas law was used to calculate gas density [12].

$$
\rho_{g}=\frac{\left(p+p_{\text {ref }}\right) M}{R T}
$$

where $M$ denotes the molecular weight of $\mathrm{CO}_{2}(44.01 \mathrm{~kg} / \mathrm{kmol}), R$ is the ideal gas constant $(0.1889 \mathrm{~kJ} / \mathrm{kg}-\mathrm{K})$, $p_{\text {ref }}$ is the reference pressure $\left(1 \times 10^{5} \mathrm{~Pa}\right)$, and $T$ is the $\mathrm{CO}_{2}$ temperature $(298 \mathrm{~K})$.

The $k-\varepsilon$ turbulence model with additional source terms was used to model turbulence between gas bubbles and the liquid. The governing equations for the turbulent kinetic energy $k$ and the dissipation rate $\varepsilon$ are respectively given as follows:

$$
\begin{aligned}
& \rho_{l} \frac{\partial k}{\partial t}-\nabla \cdot\left[\left(\mu+\frac{\mu_{T}}{\sigma_{k}}\right) \nabla k\right]+\rho_{l} u_{l} \cdot \nabla k=\frac{1}{2} \mu_{T}\left(\nabla u_{l}+\left(\nabla u_{l}\right)^{\mathrm{T}}\right)^{2}-\rho_{l} \varepsilon+S_{k} \\
& \rho_{l} \frac{\partial \varepsilon}{\partial t}-\nabla \cdot\left[\left(\mu+\frac{\mu_{T}}{\sigma_{\varepsilon}}\right) \nabla \varepsilon\right]+\rho_{l} u_{l} \cdot \nabla \varepsilon=\frac{1}{2} C_{\varepsilon 1} \frac{\varepsilon}{k} \mu_{T}\left(\nabla u_{l}+\left(\nabla u_{l}\right)^{T}\right)^{2}-\rho_{l} C_{\varepsilon 2} \frac{\varepsilon^{2}}{k}+\frac{\varepsilon}{k} C_{\varepsilon} S_{k} \\
& \mu_{T}=\frac{\rho_{l} C_{\mu} k^{2}}{\varepsilon}
\end{aligned}
$$


where $\mu_{T}$ represents the dynamic viscosity (Pass), $\sigma_{k}$ and $\sigma_{\varepsilon}$ are the turbulent Prandtl numbers, and $C_{\varepsilon 1}$ and $C_{\varepsilon 2}$ are the first and second experimental model constants, respectively. These constants are set as follows: $\sigma_{k}=1.0, \sigma_{\varepsilon}=1.3, C_{\varepsilon 1}=1.44, C_{\varepsilon 2}=1.92, C_{\varepsilon}=1.46$, and $C_{\mu}=0.09$.

The source term $S_{k}$ for the bubble-induced turbulence $\left(\mathrm{W} / \mathrm{m}^{3}\right)$ is presented as:

$$
S_{k}=-C_{k} \varphi_{g} \nabla p \cdot u_{\text {slip }}
$$

where $\varphi_{g}$ denotes the gas hold-up $\left(\mathrm{m}^{3} / \mathrm{m}^{3}\right)$ and $u_{\text {slip }}$ is the slip velocity $(\mathrm{m} / \mathrm{s})$. The bubble-induced turbulence parameter $\left(C_{k}\right)$ was set as 0.505 .

The relation for gas velocity is as follows:

$$
u_{g}=u_{l}+u_{\text {slip }}
$$

where $u_{g}, u_{l}$, and $u_{\text {slip }}$ are the gas, liquid, and slip velocities $(\mathrm{m} / \mathrm{s})$, respectively.

\subsection{Gas Dissolution}

Two-film theory was used to model mass transfer across gas and liquid interfaces during gas dissolution in the flow injection nozzle [10] [13]. This film theory uses Henry's law to model the mass transfer rate $\left(m_{g l}\right)$ in Equation (3) during $\mathrm{CO}_{2}$ dissolution in water.

$$
m_{g l}=k_{m}\left(\frac{p+p_{r e f}}{H}-c\right) M a .
$$

The interfacial area ( $a$ ) between the two phases is modeled by Euler-Euler method [14].

$$
a=(4 n \pi)^{1 / 3}\left(3 \varphi_{g}\right)^{2 / 3}
$$

where $k_{m}$ represents the mass transfer coefficient (m/s), $H$ is the Henry's constant (2980 Pa. $\left.\mathrm{m}^{3} / \mathrm{mol}\right), c$ denotes the gas concentration in liquid $\left(\mathrm{mol} / \mathrm{m}^{3}\right), M$ is the molecular weight ( $\left.44.01 \mathrm{~kg} / \mathrm{kmol}\right), a$ shows the interfacial area per volume $(1 / \mathrm{m}), n$ represents the bubbles per volume $\left(1 / \mathrm{m}^{3}\right)$, and $\varphi_{g}$ is the gas hold-up $\left(\mathrm{m}^{3} / \mathrm{m}^{3}\right)$.

Higbie's theory was used to model the mass transfer coefficient $\left(k_{m}\right)$ and is presented as follows [3] [9] [10]:

$$
k_{m}=2 \sqrt{\frac{D u_{\text {slip }}}{\pi d_{b}}}
$$

where $k_{m}$ represents the mass transfer coefficient $(\mathrm{m} / \mathrm{s}), D$ is the diffusion coefficient $\left(\mathrm{m}^{2} / \mathrm{s}\right), u_{\text {slip }}$ shows the relative velocity between gas and liquid $(\mathrm{m} / \mathrm{s})$, and $d_{b}$ is the gas bubble diameter $(\mathrm{m})$.

The growth of gas bubbles in the flow injection nozzle was modeled by using the population balance equation. The governing equation for gas bubbles population balance is as follows:

$$
\frac{\partial n}{\partial t}+\nabla \cdot\left(n u_{g}\right)=0
$$

where $n$ is the number of bubbles per volume $\left(1 / \mathrm{m}^{3}\right)$, and $u_{g}$ represents gas velocity $(\mathrm{m} / \mathrm{s})$.

The transport equation for gas concentration is shown below:

$$
\frac{\partial c}{\partial t}+\nabla c \cdot u_{l}=\nabla \cdot(D \nabla c)+\frac{m_{g l}}{M}
$$

where $D$ shows the diffusion coefficient $\left(\mathrm{m}^{2} / \mathrm{s}\right)$, and $c$ represents the dissolved gas concentration in liquid $\left(\mathrm{mol} / \mathrm{m}^{3}\right)$. The diffusion coefficient is estimated using the following equation:

$$
D=\frac{\mu_{T}}{\rho_{l}}
$$

where $\mu_{T}$ is the turbulent viscosity (Pa·s), and $\rho_{l}$ is the liquid density $\left(\mathrm{kg} / \mathrm{m}^{3}\right)$.

\section{Numerical Method and Implementation}

Commercial code COMSOL-Multiphysics (V 4.3) was used to model two-phase flow mixing with mass trans- 
port in the flow injection nozzle. Three CRs were simultaneously solved using the $k$ - $\varepsilon$ turbulence model and mass transport equations for dissolved gas. A time-dependent solver was used to simulate the two-phase flow with mass transfer for $40 \mathrm{~s}$ and at a time step of $0.001 \mathrm{~s}$. Geometric models were discretized using a free triangular mesh type with 3472 domain and 275 boundary elements. All computations were performed on an Intel Core i7-3370 $3.90 \mathrm{GHz}$ processor with a 16 GB RAM operating system.

\section{Results and Discussion}

\subsection{Gas Hold-Up}

The effect of CR on the average gas hold-up with variation in inlet gas velocities is presented in Figure 2. These results were estimated using an inlet liquid velocity of $0.0001 \mathrm{~m} / \mathrm{s}$ and a gas bubble size of $0.002 \mathrm{~m}$. Gas hold-up showed a direct relationship to the gas flow rates, that is, the gas hold-up increased with increasing inlet gas velocity. Higher gas flow rates enhanced the accumulation of gas bubbles in the nozzle, thereby increasing liquid circulation. This condition implies that carbonation is more effective at high gas flow rates because of high gas dissolution caused by improved liquid recirculation. The gas hold-up significantly increased when the nozzle throat area was reduced. The flow injection nozzle with the CR value of 4 considerably improved the liquid recirculation because of high amount of gas hold-up. Hence, the carbonation process in nozzles with larger CRs and inlet gas velocities increased because of the high volume of gas in liquid [1] [9]. Gas hold-up reduced with increasing liquid flow rates because of decreased liquid recirculation (Figure 3). The results were estimated using an inlet gas velocity of $0.0005 \mathrm{~m} / \mathrm{s}$ and a gas bubble size of $0.002 \mathrm{~m}$. Increasing liquid velocity decreased the gas dissolution process because of less effective flow mixing of gas with liquid. Therefore, nozzles with larger CRs values and less liquid velocities are suitable for preparing carbonated water because of the larger volume of gas accumulation and improved liquid recirculation [9].

\subsection{Gas Concentration}

The effect of inlet gas velocities with different CRs on average gas concentration is presented in Figure 4. The results were evaluated at an inlet liquid velocity of $0.0001 \mathrm{~m} / \mathrm{s}$ and a constant gas bubble size of $0.002 \mathrm{~m}$. Gas concentration showed an increasing slope with respect to gas flow rates because of improved liquid circulation in the nozzle. The maximum gas concentration in the liquid was observed at high gas velocities, showing that carbonation increased at high gas velocities because of increasing gas concentration in the liquid. Gas concentration also exhibited a direct relationship to nozzle CRs. The reduction in the nozzle throat increased gas dissolution by improving liquid recirculation, which in turn increased the gas concentration level in water. The nozzle with a CR of 4 exhibited the highest gas concentration magnitude and enhanced carbonation. These findings imply that the nozzle throat with high CRs and gas flow rates would increase carbonation because of high gas concentrations caused by effective liquid recirculation [5] [9] [15].

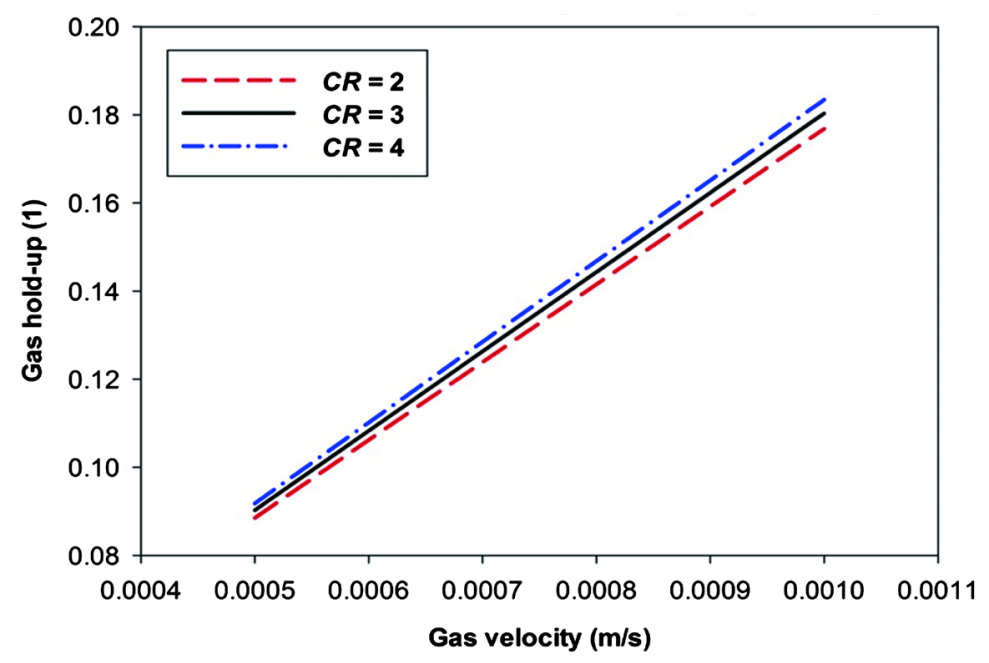

Figure 2. Gas hold-up (1) with variations in inlet gas velocity (m/s). 


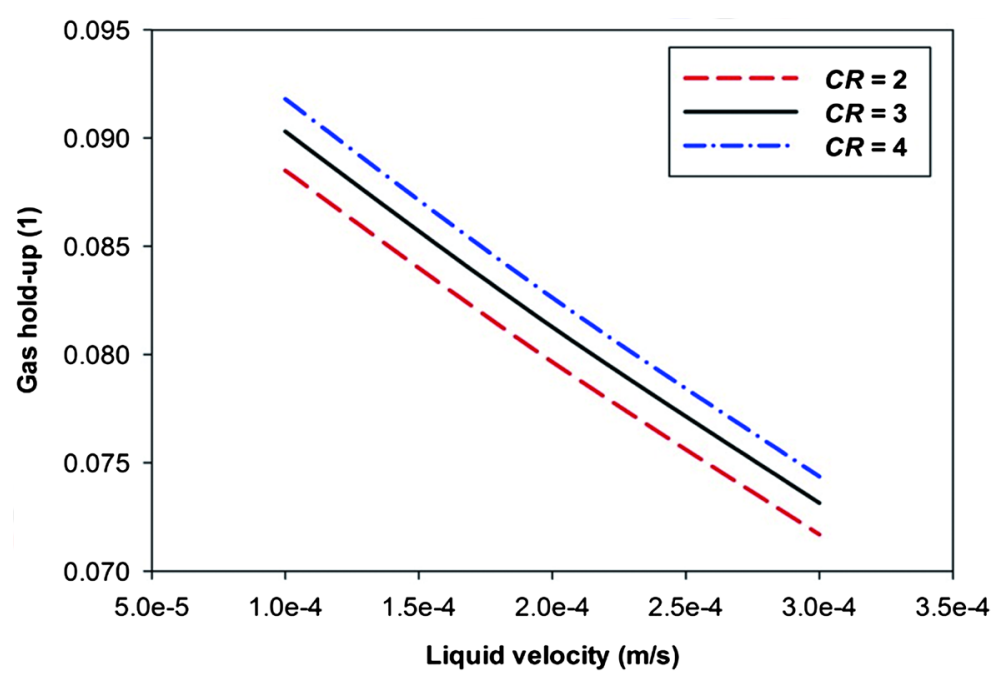

Figure 3. Gas hold-up (1) with variations in inlet liquid velocity (m/s).

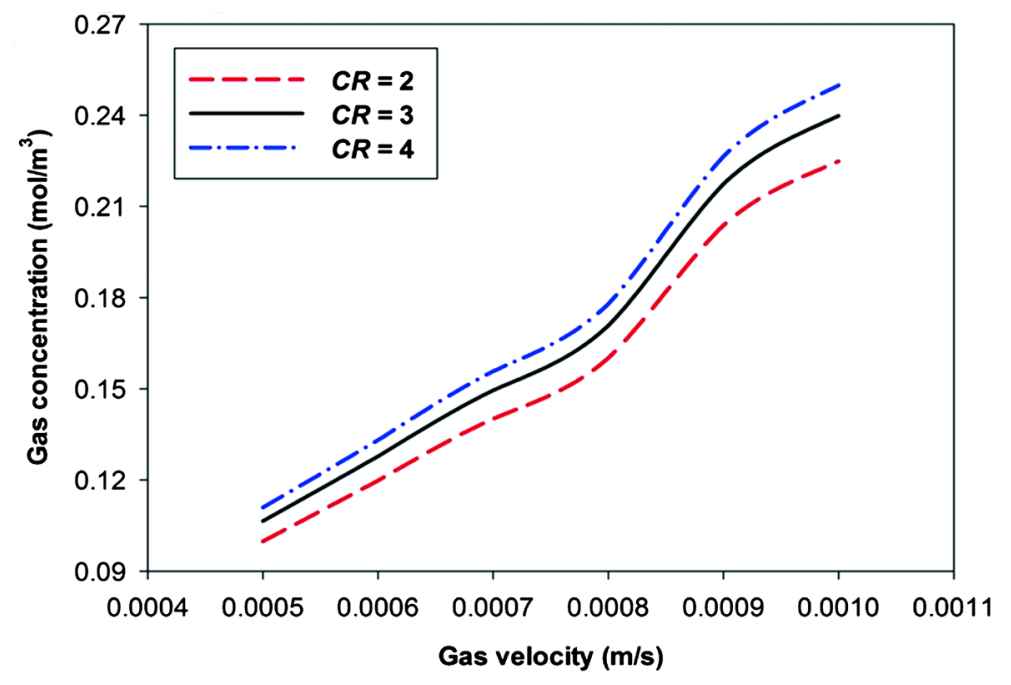

Figure 4. Gas concentration $\left(\mathrm{mol} / \mathrm{m}^{3}\right)$ with variations in gas velocity $(\mathrm{m} / \mathrm{s})$.

Figure 5 shows the average gas concentration with the effect of different CR values and liquid velocities at an inlet gas velocity of $0.0005 \mathrm{~m} / \mathrm{s}$ and bubble size of $0.002 \mathrm{~m}$. The results showed that increasing the water flow rates decreased gas concentration because of less effective liquid recirculation in the nozzle. The slope of gas concentration significantly decreased because of less effective flow mixing caused by increasing liquid flow velocities. Carbonation was significantly reduced in the nozzles with smaller CR because of low liquid recirculation, which is due to high liquid flow rates. Flow mixing in the nozzle can be increased by increasing gas flow rates to improve liquid recirculation. The results suggest that larger CRs and low liquid velocities are necessary to increase carbonation efficiency by increasing the gas concentration magnitude in the liquid [5] [15]. Gas bubble size is an important parameter in the study of the two-phase flow system because this parameter can affect gas dissolution [15]. Therefore, the effect of gas bubble size on the average gas concentration with different CRs is illustrated in Figure 6. The results are evaluated with an inlet gas velocity of $0.0005 \mathrm{~m} / \mathrm{s}$, water velocity of $0.0001 \mathrm{~m} / \mathrm{s}$, and gas bubble size of $0.002 \mathrm{~m}$. Gas concentration significantly decreased with the use of larger gas bubbles because of reduction in gas dissolution. The results depict the difficulty in dissolving larger gas bubbles in the liquid. Therefore, gas concentration level in the nozzle was reduced at larger gas bubble diameters. The nozzle with a CR of 4 showed high gas concentration magnitudes at different gas bubble sizes than the other models. Therefore, small gas bubbles and larger CR are suitable for carbonation because of high gas concentration in the nozzle [9] [15]. 


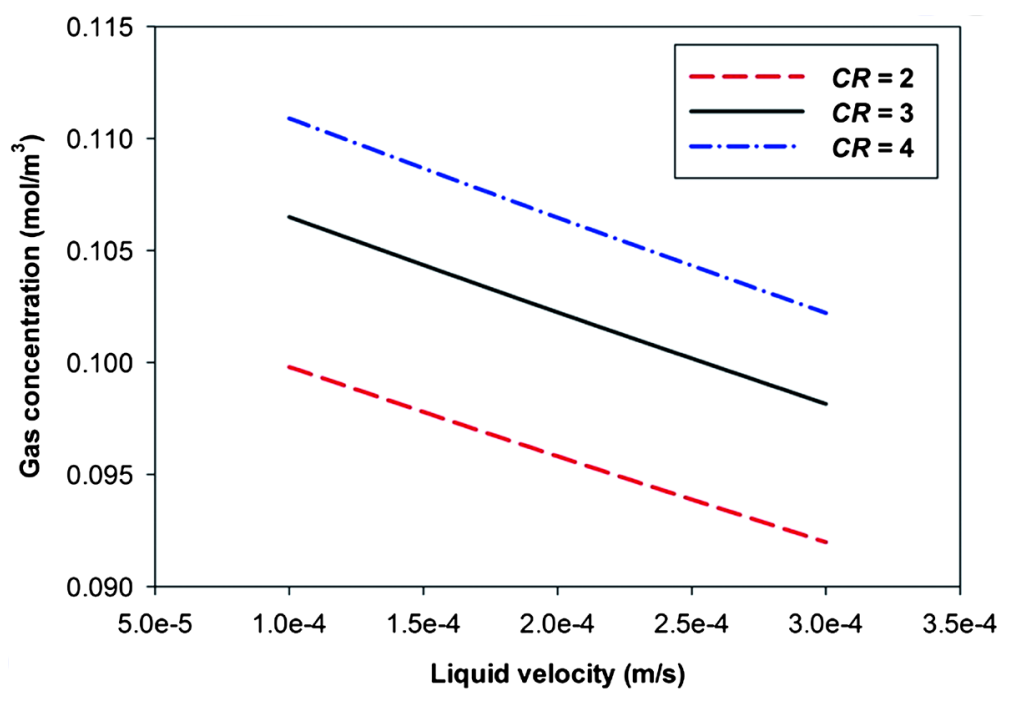

Figure 5. Gas concentration $\left(\mathrm{mol} / \mathrm{m}^{3}\right)$ with variations in liquid velocity $(\mathrm{m} / \mathrm{s})$.

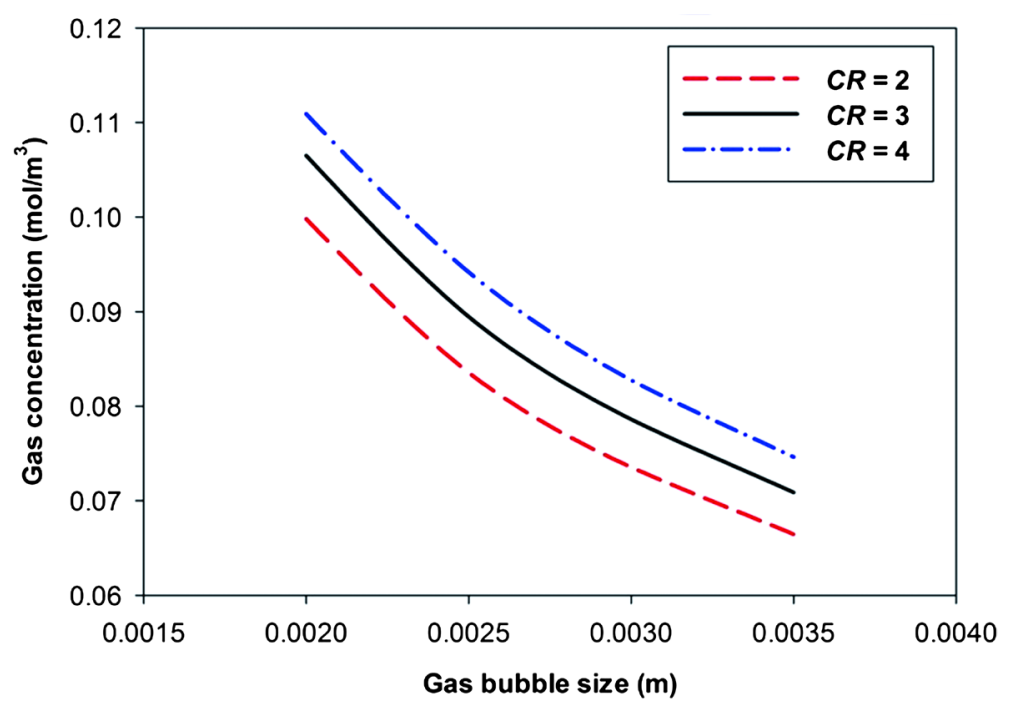

Figure 6. Gas concentration $\left(\mathrm{mol} / \mathrm{m}^{3}\right)$ with variations in gas bubble size $(\mathrm{m})$.

\subsection{Mass Transfer Coefficient}

The effect of various gas velocities on the average mass transfer coefficient with a CR of 3, liquid velocity of $0.0001 \mathrm{~m} / \mathrm{s}$, and gas bubble size of $0.002 \mathrm{~m}$ is shown in Figure 7. The mass transfer coefficient showed higher magnitude in the lower part of the nozzle, particularly at low gas velocities, because of the presence of gas inlet in this section. Gas dissolution in liquid was higher in the lower region of the flow injection nozzle because of the higher magnitude of mass transfer coefficient in the area. Mass transfer between the two fluids was lower in the upper part and throat of the nozzle because of higher liquid velocity in these areas. High liquid velocity resulted in low carbonation because of less effective flow mixing. Increasing the gas velocities enhanced the mass transfer mechanism in the entire nozzle geometry. Mass transfer was observed in the upper and lower sections of the nozzle at a maximum gas velocity of $0.001 \mathrm{~m} / \mathrm{s}$. These findings show that carbonation is strong in the lower portion but weak in the throat and upper part of the flow injection nozzle [4] [5]. The average mass transfer coefficient was also estimated by determining the effect of different CRs and gas velocities at an inlet liquid velocity of $0.0001 \mathrm{~m} / \mathrm{s}$ and a constant gas bubble size $0.002 \mathrm{~m}$ (Figure 8). The mass transfer coefficient almost linearly increased with increasing inlet gas velocities for all cases of CRs. The nozzle with high CR values yielded higher magnitudes of the mass transfer coefficient, indicating that mass transfer between gas and liquid is high 


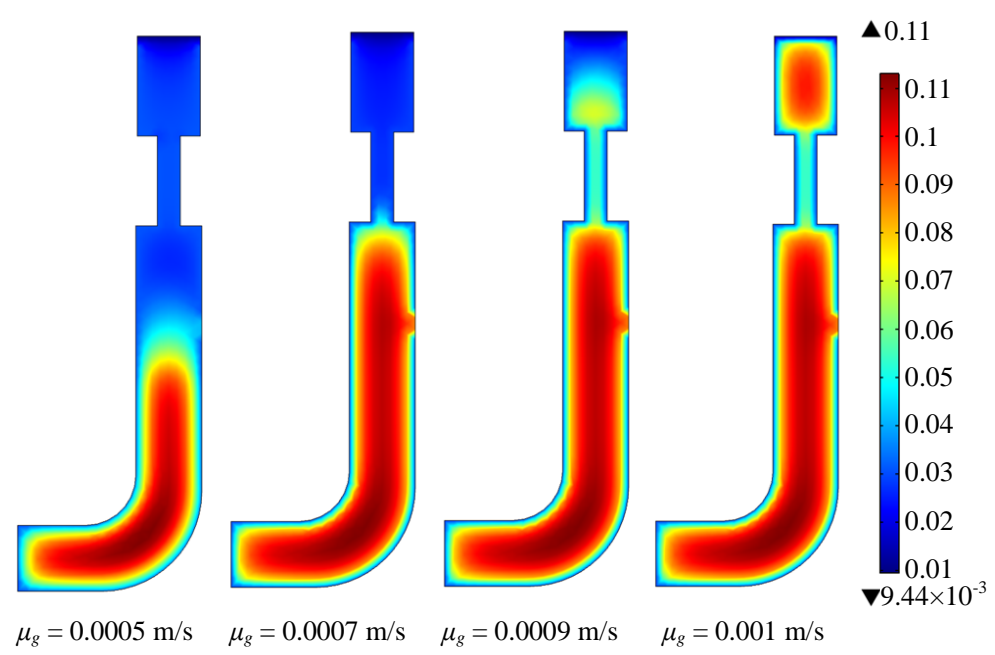

Figure 7. Mass transfer coefficient $(\mathrm{m} / \mathrm{s})$ in the nozzle with $\mathrm{CR}=3$ at inlet gas and liquid velocities of 0.0005 and $0.0001 \mathrm{~m} / \mathrm{s}$, respectively.

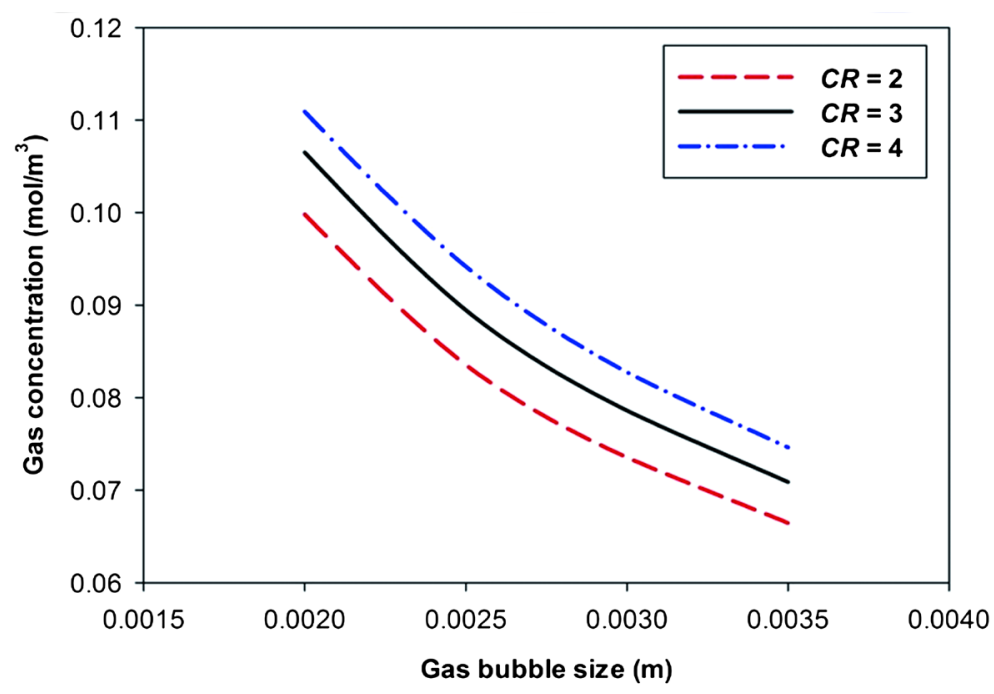

Figure 8. Mass transfer coefficient $(\mathrm{m} / \mathrm{s})$ with variations in gas velocity $(\mathrm{m} / \mathrm{s})$.

in nozzles with smaller CR. This result suggests the dependence of mass transfer coefficient on gas flow rates and nozzle geometry (CR). Therefore, higher gas velocities and CR are recommended to increase carbonation efficiency [3] [15].

Figure 9 shows the average mass transfer coefficient with the effect of different CRs and liquid velocities at an inlet gas velocity of $0.0005 \mathrm{~m} / \mathrm{s}$ and a bubble size of $0.002 \mathrm{~m}$. Mass transfer coefficient significantly decreased with increasing liquid flow velocities because of less effective flow mixing. Mass transfer between the two fluids reduced linearly in the nozzle of small CRs because high liquid velocities caused a reduction in liquid recirculation. Nozzles with larger CRs increased carbonation because of increased mass transfer coefficient. Therefore, larger CRs and lower water flow rates must be selected to enhance carbonation by improving the mass transfer mechanism between gas and liquid [3] [9]. The effect of gas bubble size on mass transfer coefficient with different CRs is presented in Figure 10. The results were evaluated at an inlet gas velocity of 0.0005 $\mathrm{m} / \mathrm{s}$, water velocity of $0.0001 \mathrm{~m} / \mathrm{s}$, and gas bubble size of $0.002 \mathrm{~m}$. The mass transfer coefficient decreased linearly with increasing gas bubble size because mass transfer between the gas and liquid phases with larger gas bubbles is difficult. Moreover, the nozzle with a CR of 4 yielded higher mass transfer coefficient magnitudes than other CR cases. These results suggest that larger CRs and an appropriate gas bubble size must be selected to enhance carbonation by improving the mass transfer mechanism in the flow injection nozzle [4] [5]. 


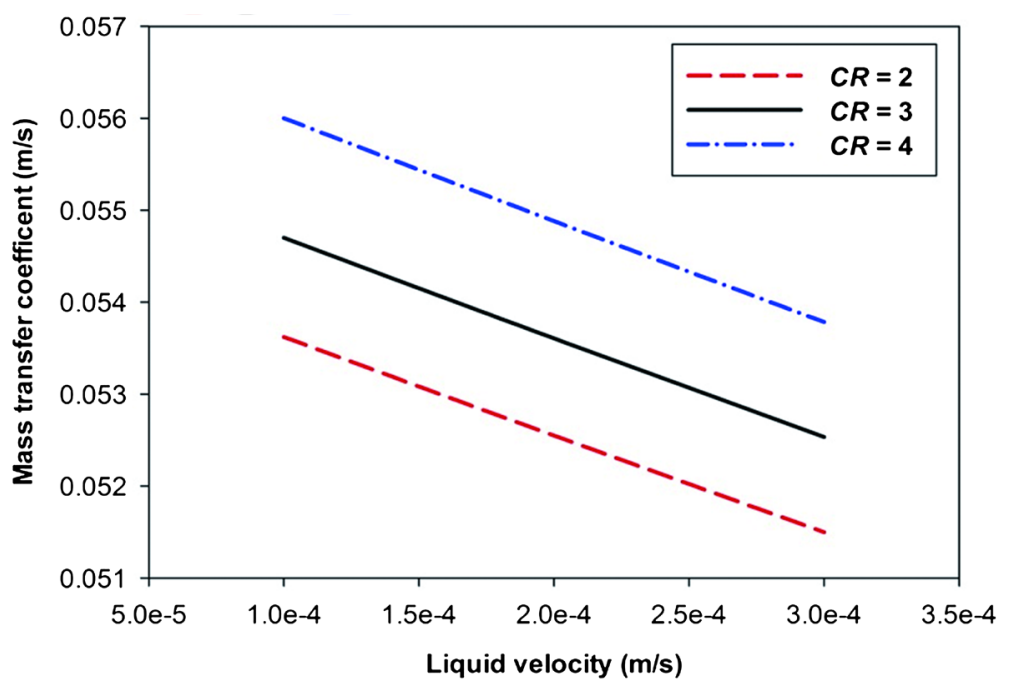

Figure 9. Mass transfer coefficient $(\mathrm{m} / \mathrm{s})$ with variations in liquid velocity $(\mathrm{m} / \mathrm{s})$.

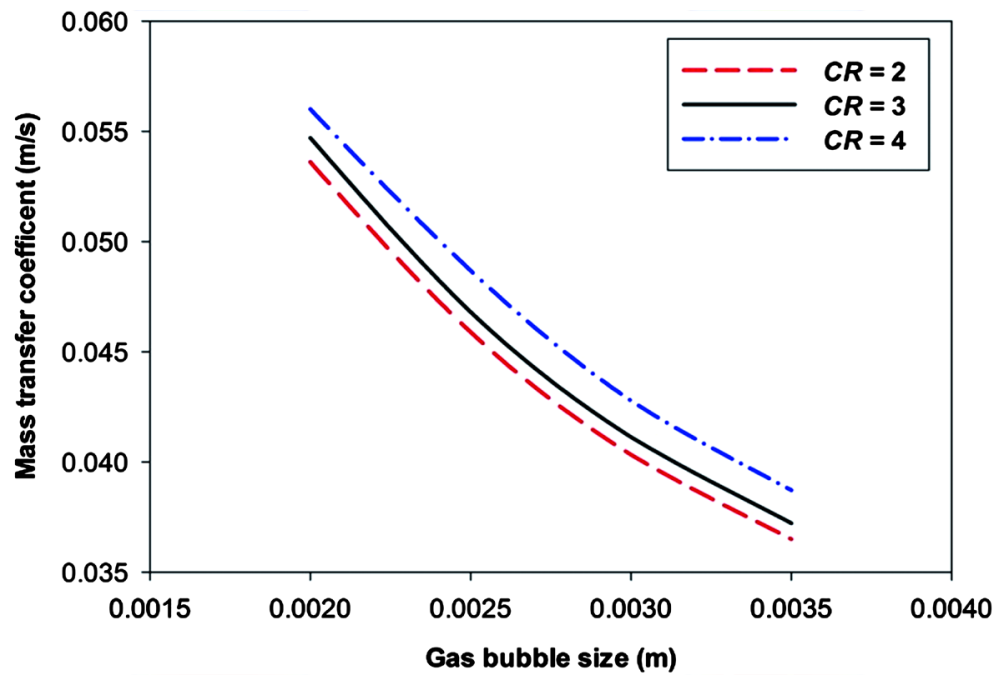

Figure 10. Mass transfer coefficient $(\mathrm{m} / \mathrm{s})$ with variations in gas bubble size (m).

\section{Conclusion}

This study investigated the effects of contraction ratio on gas-liquid flow mixing with mass transfer in the flow injection nozzle. Euler-Euler two-fluid method was used to model the two-phase flow in the flow injection nozzle. The nozzle geometry was modified with the addition of a gas inlet hole and throat to enhance gas dissolution. Various contraction ratios of nozzle throat, inlet gas and liquid velocities, and gas bubble sizes were used to determine their effects on gas hold-up, gas concentration, and mass transfer coefficient.

The flow injection nozzle with the maximum CR improved liquid recirculation, which is caused by larger gas hold-up volume. Carbonation was enhanced at higher gas flow velocities because of enhanced gas dissolution. Gas hold-up decreased with increasing liquid flow velocities because of less liquid recirculation. Gas concentration increased linearly with increasing CRs and gas flow velocities. By contrast, gas concentration was reduced with increasing liquid velocities because of less effective flow mixing. Gas bubbles with larger size decreased gas concentration by reducing gas dissolution in liquid. The mass transfer coefficient was high in the lower part of the flow injection nozzle. High CR values resulted in higher magnitudes of the mass transfer coefficient, which showed inverse relationships to liquid flow rates and gas bubble sizes. High CRs of the flow injection 
nozzle with higher gas flow velocities, lower liquid velocities, and small gas bubbles are suitable for effective carbonation.

\section{Acknowledgements}

This work was supported by the High Value-added Food Technology Development Program, Ministry of Agriculture, Food, and Rural Affairs (No. 314051-03-1-HD020), and the grant from the Priority Research Centers Program through the NRF as funded by MEST (No. 2010-0020089).

\section{References}

[1] Becker, S., Sokolichin, A. and Eigenberger, G. (1994) Gas-Liquid Flow in Bubble Columns and Loop Reactors: Part II. Comparison of Detailed Experiments and Flow Simulations. Chemical Engineering Science, 49, 5747-5762. http://dx.doi.org/10.1016/0009-2509(94)00290-8

[2] Russell, A.B., Thomas, C.R. and Lilly, M.D. (1995) Oxygen Transfer Measurements during Yeast Fermentations in a Pilot Scale Airlift Fermenter. Bioprocess Engineering, 12, 71-79. http://dx.doi.org/10.1007/BF01112996

[3] Juraščík, M. Blažej, M. Annus, J. and Markoš, J. (2006) Experimental Measurements of Volumetric Mass Transfer Coefficient by the Dynamic Pressure-Step Method in Internal Loop Airlift Reactors of Different Scale. Chemical Engineering Journal, 125, 81-87. http://dx.doi.org/10.1016/j.cej.2006.08.013

[4] Deckwer, W.-D., Nguyen-Tien, K., Schumpe, A. and Serpemen, Y. (1982) Oxygen Mass Transfer into Aerated CMC Solutions in a Bubble Column. Biotechnology and Bioengineering, 24, 461-481. http://dx.doi.org/10.1002/bit.260240215

[5] Chisti, Y. and Jauregui-Haza, U.J. (2002) Oxygen Transfer and Mixing in Mechanically Agitated Airlift Bioreactors. Biochemical Engineering Journal, 10, 143-153. http://dx.doi.org/10.1016/S1369-703X(01)00174-7

[6] Chakraborty, D., Guha, M. and Banerjee, P.K. (2009) CFD Simulation on Influence of Superficial Gas Velocity, Column Size, Sparger Arrangement, and Taper Angle on Hydrodynamics of the Column Flotation Cell. Chemical Engineering Communications, 196, 1102-1116. http://dx.doi.org/10.1080/00986440902897376

[7] Alves, M.A., Oliveira, P.J. and Pinho, F.T. (2004) On the Effect of Contraction Ratio in Viscoelastic Flow through Abrupt Contractions. Journal of Non-Newtonian Fluid Mechanics, 122, 117-130. http://dx.doi.org/10.1016/j.jnnfm.2004.01.022

[8] Evans, R.E. and Walters, K. (1986) Flow Characteristics Associated with Abrupt Changes in Geometry in the Case of Highly Elastic Liquids. Journal of Non-Newtonian Fluid Mechanics, 20, 11-29. http://dx.doi.org/10.1016/0377-0257(86)80013-1

[9] Ali, H., Kim, K.W., Kwak, M.K., Kim, J.S., Choi, J.Y. and Park C.W. (2015) Numerical Investigation on the Flow Mixing Feature inside a Continuously Carbonating Process Tank. Computers \& Electrical Engineering (in Press). http://dx.doi.org/10.1016/j.compeleceng.2015.09.002

[10] Ali, H., Cheema, T.A. and Park C.W. (2015) Numerical Modeling of Two-Phase Bubbly Flow Mixing with Mass Transport in an Effective Microorganism Odor Removing System. Journal of Chemical Technology and Biotechnology. http://dx.doi.org/10.1002/jctb.4674

[11] Lestinsky, P., Vayrynen, P., Vecer, M. and Wichterle, K. (2012) Hydrodynamics of Airlift Reactor with Internal Circulation Loop: Experiment vs. CFD Simulation. Procedia Engineering, 42, 892-907. http://dx.doi.org/10.1016/j.proeng.2012.07.482

[12] Sommerfeld, M. (2004) Bubbly Flows. Springer, Berlin Heidelberg. http://dx.doi.org/10.1007/978-3-642-18540-3

[13] Talvy, S., Cockx, A. and Liné, A. (2007) Modeling of Oxygen Mass Transfer in a Gas-Liquid Airlift Reactor. AIChE Journal, 53, 316-326. http://dx.doi.org/10.1002/aic.11075

[14] Cockx, A., Do-Quang, Z., Liné, A. and Roustan, M. (1999) Use of Computational Fluid Dynamics for Simulating Hydrodynamics and Mass Transfer in Industrial Ozonation Towers. Chemical Engineering Science, 54, 5085-5090. http://dx.doi.org/10.1016/S0009-2509(99)00239-0

[15] Bouaifi, M., Hebrard, G., Bastoul, D. and Roustan, M. (2001) A Comparative Study of Gas Hold-Up, Bubble Size, Interfacial Area and Mass Transfer Coefficients in Stirred Gas-Liquid Reactors and Bubble Columns. Chemical Engineering and Processing, 40, 97-111. http://dx.doi.org/10.1016/S0255-2701(00)00129-X 